\title{
70-lecie Oddziału Morskiego Polskiego Towarzystwa Dermatologicznego
}

\author{
Gdańsk 1946-2016
}

Przegl Dermatol 2016, 103, 500-503

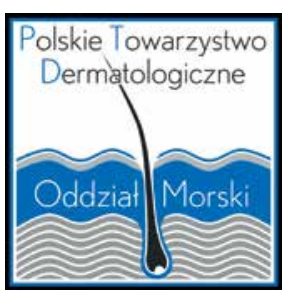

W tym roku obchodzimy jubileusz 70-lecia Oddziału Morskiego Polskiego Towarzystwa Dermatologicznego (OM PTD). Oddział Morski PTD został powołany do życia wczesną wiosną 1946 roku. Od początku działalność Oddziału była ściśle związana z gdańską Kliniką Dermatologiczną, która powstała w 1945 roku. Twórcami Oddziału byli wybitni dermatolodzy i wenerolodzy wykształceni jeszcze w okresie międzywojennym w znakomitych polskich ośrodkach naukowych, takich jak Kraków, Warszawa, Wilno i Lwów.

Do grona założycieli i szczególnie aktywnych członków Oddziału należy zaliczyć profesorów: Tadeusza Pawlasa (ryc. 1), Jerzego Kozakiewicza, Zbigniewa Oniska. Dużą rolę w pierwszym okresie działalności OM PTD odegrali m.in. lekarze: dr med., dr med. Kazimierz Bandych, Irena Gołębiowska, Eustachiusz Chodyń, Witold Jankowski, Stanisław Krajewski, Roman Przylipiak, Anna Komorowska, Zofia Doburzyńska-Anisimowicz, Marian Krzyżanowski, Wilhelm Bartkiewicz, Zbigniew Warczewski, MichałKorycki. To oni nadaliOddziałowi Morskiemu PTD charakterystyczny i trwały rys - bardzo ścisły

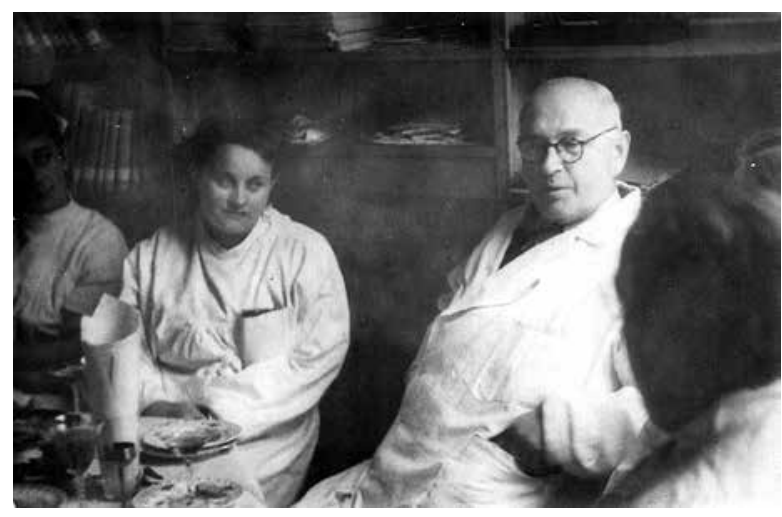

Rycina I. Pierwszy przewodniczący OM PTD prof. T. Pawlas i dr I. Gołębiowska kontakt i współpracę grona naukowców, skupionych głównie w Klinice Dermatologicznej Akademii Medycznej w Gdańsku (AMG) z praktyką dermatologiczną $\mathrm{w}$ terenie. Swoistym spiritus movens wśród członków założycieli był dr med. Stanisław Pawłowski, wieloletni adiunkt Katedry i Kliniki Dermatologicznej AMG, zastępca prof. T. Pawlasa, późniejszy ordynator Oddziału Dermatologicznego w Szpitalu Morskim w Gdyni-Redłowie, który swą wyjątkową osobowością roztaczał zawsze aurę życzliwości i twórczej zachęty, zwłaszcza w stosunku do młodych dermatologów, a także dr med. Aisza Szumska-Markiewicz, organizatorka Wojewódzkiej Przychodni Dermatologicznej w Gdańsku i pierwszy jej dyrektor, twórczyni sieci poradni dermatologicznych w Trójmieście i województwie gdańskim, współinicjatorka akcji „W”, czyli zwalczania powojennej epidemii kiły na terenie gdańskiego wybrzeża. W kolejnych latach do grona tego dołączyli m.in. dr med., dr med. Wacław Arasimowicz - uczeń prof. Lenartowicza, Józef Lipski, Maksymilian Obezjaninow, Alina Oziewicz-Ziembińska, Jerzy Krzywiec, Włodzimierz Wołodźko, Zbigniew Żak, Leon Binek, Andrzej Wężyk, Tadeusz Mierzwiński, Kazimierz Szawłowski. To właśnie w tamtych latach ustaliła się niezwykle skuteczna do dziś forma zarówno stałe-

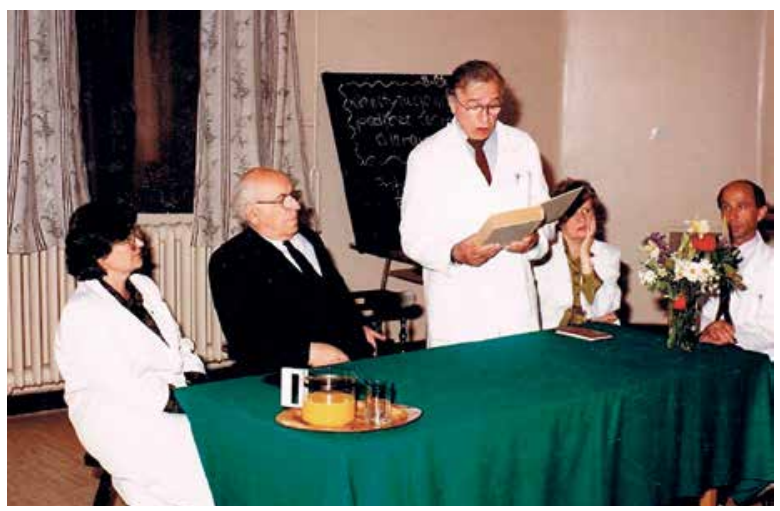

Rycina 2. Profesor H. Szarmach przewodniczy uroczystemu zebraniu OM PTD z udziałem prof. Racza 


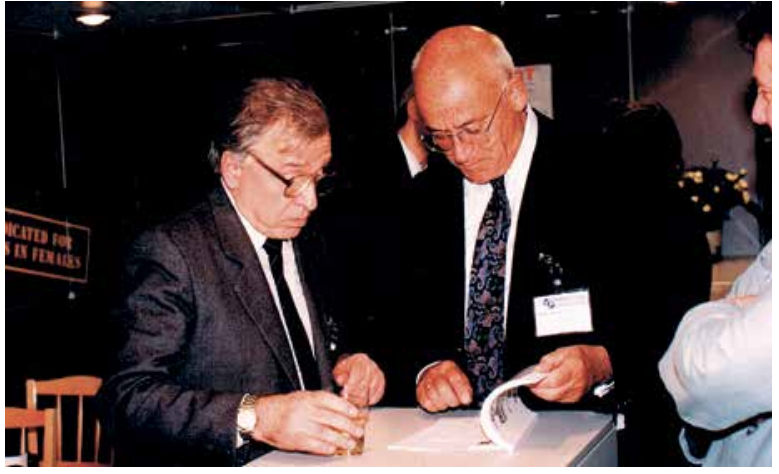

Rycina 3. Profesor O. Braun-Falco i prof. H. Szarmach podczas XXIV Zjazdu PTD w Gdańsku w 1992 roku

go podnoszenia kwalifikacji zawodowych, jak i środowiskowej integracji dermatologów zrzeszonych w OM PTD, mianowicie organizowane raz w miesiącu zebrania naukowo-szkoleniowe. Prowadzone na nich wykłady, dyskusje i prezentacje dotyczyły zarówno najnowszych zdobyczy naukowych w dermatologii i wenerologii, jak i praktycznych zadan i problemów w sieci ambulatoryjnego lecznictwa dermatologicznego.

Wykłady naukowo-szkoleniowe w ramach comiesięcznych zebrań OM PTD, oprócz pracowników naukowo-dydaktycznych gdańskiej Kliniki Dermatologicznej, prowadzili także znani i wybitni naukowcy oraz dydaktycy dermatologii $z$ innych ośrodków z kraju i zagranicy, m.in. profesorowie: F. Kogoj z Zagrzebia, R. Degos z Paryża, Hellerström ze Sztokholmu, K. Linzer z Berlina, I. Racz (ryc. 2) i Szatmary z Węgier, Romanienko, Szekłakow, Arawijskij i Studnicyn z ośrodków rosyjskich, Kleine-Natrop z Drezna, Obrtel z Pragi, Pflegel z Rostoku, Haustein z Lipska, H. Schubert z Erfurtu, Wolmer z Bremy, Bart z Drezna, J. Wenning ze Schwarzwaldu, J. Bos z Amsterdamu, R. Schwartz z USA, A. Sergeev z Moskwy. Na szczególne miejsce w tym gronie zasługują nazwiska takich dermatologicznych sław, jak profesorowie Otto Braun-Falco (ryc. 3) i Enno Christophers z Niemiec, którzy w 1992 roku byli także gośćmi XXIV Zjazdu Polskiego Towarzystwa Dermatologicznego w Gdańsku.

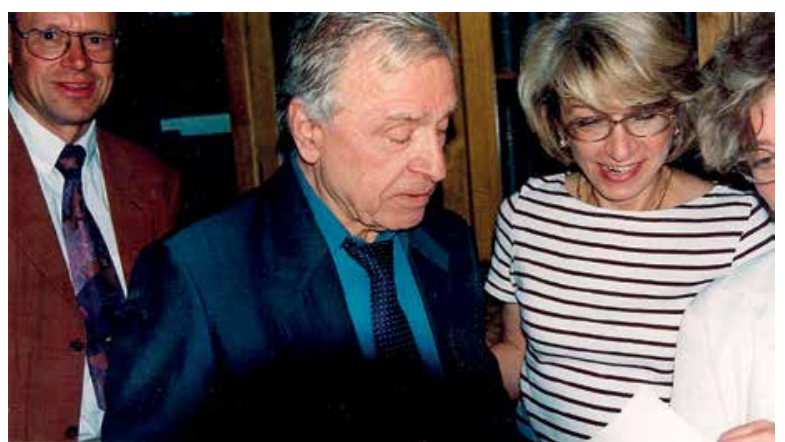

Rycina 5. Goście ze Szwecji w Klinice Dermatologicznej w Gdańsku ( 1994 rok)

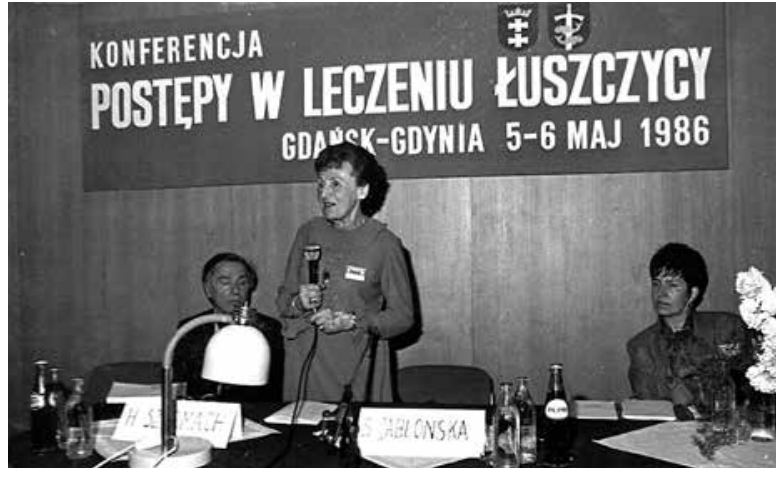

Rycina 4. Profesor S. Jabłońska przewodniczy sesji na konferencji „Postępy w leczeniu łuszczycy” w Gdańsku

Oddział Morski PTD w Gdańsku zawsze dbał o rozwój przyszłych talentów dermatologicznych. Dzięki kontaktom z pokrewnymi ośrodkami i organizacjami zagranicznymi młodzi, wyróżniający się adepci dermatologii mogli odbywać staże zagraniczne (m.in. J. Kozakiewicz, H. Szarmach, W. Placek, R. Nowicki, M. Sokołowska-Wojdyło, W. Barańska-Rybak).

Dwukrotnie w swej historii Oddział Morski PTD był organizatorem zjazdów Polskiego Towarzystwa Dermatologicznego. Przy współpracy z Katedrą i Kliniką Dermatologiczną AMG był ich gospodarzem w maju 1961 roku (XVII Zjazd) i we wrześniu 1992 roku (XXIV Zjazd). Perfekcyjną organizacją XXIV Zjazdu PTD (jeszcze bez pomocy firmy organizacyjnej) kierował prof. Henryk Szarmach - ówczesny kierownik Katedry i Kliniki Dermatologicznej w Gdańsku i przewodniczący Oddziału Morskiego. W Gdańsku odbywały się też liczne sympozja i konferencje naukowe, choćby konferencje Sekcji Wenerologicznej PTD w 1967 i 1978 roku czy sympozja na temat postępów w leczeniu łuszczycy (maj 1986 roku) (ryc. 4) oraz chorób zawodowych i alergicznych (wrzesień 1993 roku).

W maju 1994 roku z inicjatywy prof. Szarmacha odbyło się wspólne posiedzenie naukowe członków Oddziału Morskiego z grupą dermatologów (15 osób) z Karlskrone, członków Szwedzkiego Towarzystwa Dermatologicznego (ryc. 5).

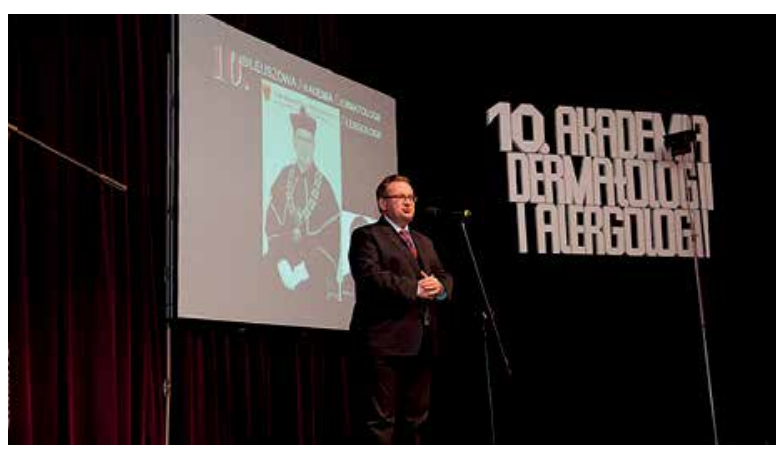

Rycina 6. Prezes ZG PTD prof. Jacek Szepietowski otwiera 10. Akademię Dermatologii i Alergologii (Słupsk, 6 lutego 2014 roku) 


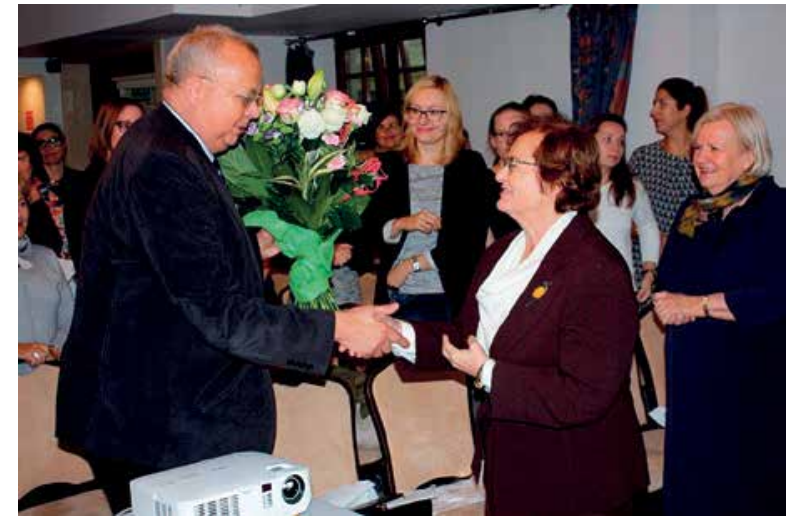

Rycina 7. Jubileuszowe zebranie OM PTD, październik 2016 roku - prof. R. Nowicki składa podziękowania prof. J. Roszkiewicz za długoletnie przewodniczenie OM PTD

Również w ostatnim dziesięcioleciu członkowie OM PTD przy współudziale Kliniki byli organizatorami bądź współorganizatorami wielu wydarzeń naukowych: Sympozjum Gdańskiego Ośrodka Mastocytoz (lipiec 2005 roku), II Konferencji Naukowej „Stan zachowania i antropogeniczne przemiany jezior raduńskich" (Ostrzyce, październik 2005 roku), X Jubileuszowej Konferencji Sekcji Dermatochirurgii PTD (Jurata, wrzesień 2007 roku), XIII Konferencji Naukowo-Szkoleniowej Sekcji Dermatochirurgii i VI Konferencji Sekcji Dermatologii Dziecięcej PTD (Jastrzębia Góra, czerwiec 2011 roku), XXIV Sympozjum Sekcji Alergologicznej PTD (Sopot, październik 2011 roku), VII Konferencji Sekcji Dermatologii Estetycznej PTD (Gdańsk, maj 2013 roku), XIV Konferencji Sekcji Dermatochirurgii i VII Konferencji Sekcji Dermatologii Dziecięcej PTD (Jastrzębia Góra, czerwiec 2013 roku).

Od 12 lat członkowie OM PTD aktywnie uczestniczą w organizacji corocznych międzynarodowych spotkań alergologów i dermatologów odbywających się w Słupsku i w Ustce w ramach Akademii Alergologii i Dermatologii, które wpisały się na stałe do kalendarza najważniejszych wydarzeń alergologicznych i dermatologicznych w Polsce (ryc. 6).

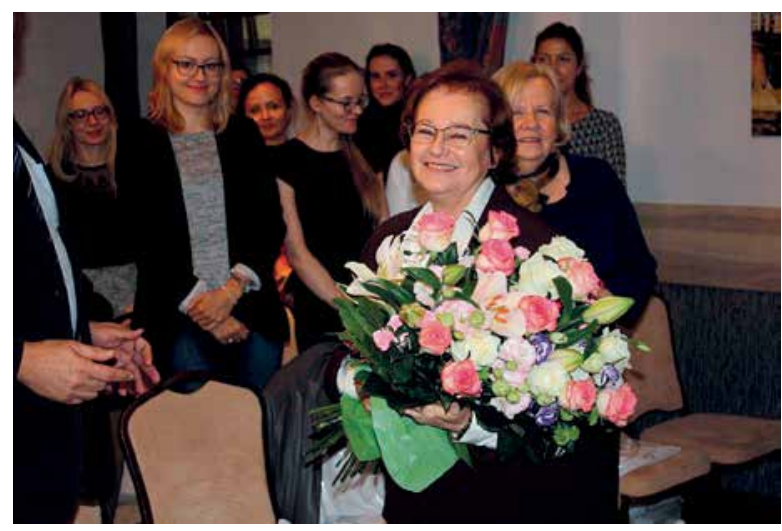

Rycina 9. Profesor J. Roszkiewicz w otoczeniu lekarzy

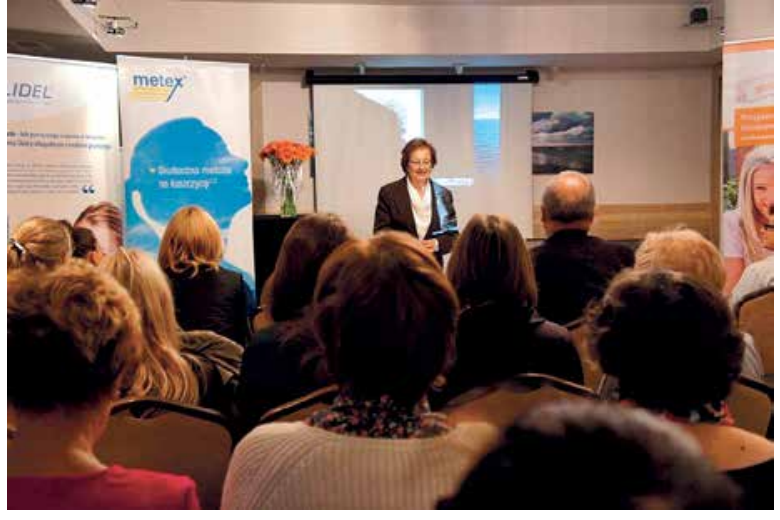

Rycina 8. Wystąpienie prof. J. Roszkiewicz (październik 2016 roku)

Ponadto od 2010 roku członkowie Oddziału są także organizatorami corocznych spotkań Sekcji Chłoniaków Skóry Polskiej Grupy Badawczej Chłoniaków. Biorą również aktywnie udział w szkoleniu podyplomowym, organizując kursy specjalizacyjne i doskonalące dla dermatologów i alergologów. Kilku członków Oddziału uczestniczy w pracach międzynarodowych towarzystw alergologicznych i dermatologicznych, a także zasiada w komitetach redakcyjnych czasopism naukowych.

Od początku działalności i w następnych okresach, często kilkakrotnie, funkcje kierownicze w Oddziale Morskim PTD (prezesi, wiceprezesi) sprawowali: T. Pawlas, S. Krajewski, S. Pawłowski, E. Chodyń, F. Miedziński, J. Kozakiewicz, J. Filipiuk, G. Kuszyńska-Cieślik, W. Placek, H. Szarmach, J. Roszkiewicz (ryc. 7-9), A. Wilkowska. Sekretarzami byli natomiast m.in. J. Kozakiewicz, H. Kamińska, H. Szarmach, H. Pawlik, L. Wiewiórkowska-Pujanek, A. Wilkowska, E. Grubska-Suchanek. Od 2014 roku przewodniczącym Oddziału Morskiego PTD jest prof. Roman Nowicki, który kontynuuje tradycję swoich poprzedników, organizując comiesięczne zebrania naukowo-szkoleniowe (ryc. 10).

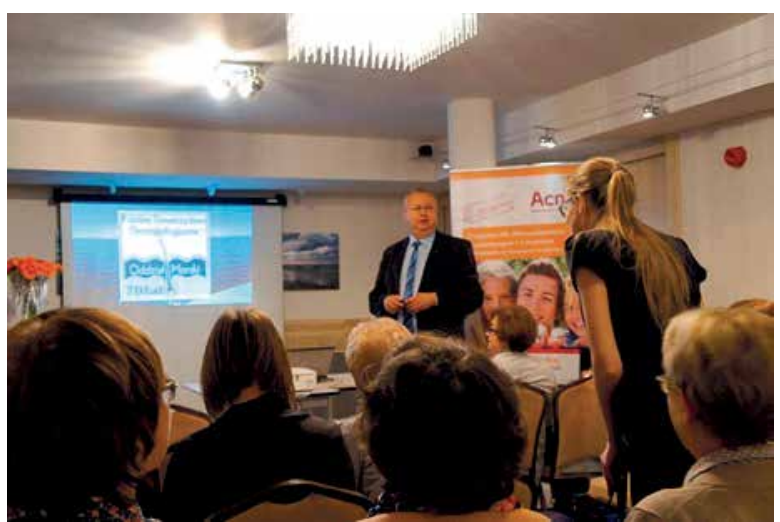

Rycina 10. Jubileuszowe zebranie OM PTD, październik 2016 roku - wykład prof. R. Nowickiego 
Spotykamy się w każdą drugą środę miesiąca, aby wysłuchać wykładów dermatologów z naszego regionu i gości z innych ośrodków klinicznych, autorytetów zarówno w dziedzinie chorób skóry, jak również $\mathrm{w}$ zakresie chorób wewnętrznych, alergologii, kardiologii, reumatologii, chorób zakaźnych, okulistyki, chirurgii, kardiochirurgii i medycyny ratunkowej. Ponadto na każdym posiedzeniu przedstawiane są ciekawe przypadki kliniczne, co jest okazją do wy- miany doświadczeń na temat różnych problemów diagnostycznych i terapeutycznych, które pojawiają się w codziennej praktyce. W większości zebrań Oddziału uczestniczą firmy farmaceutyczne, które przy okazji tych spotkań mają możliwość przedstawienia lekarzom informacji na temat najnowszych produktów medycznych i kosmetycznych.

Elżbieta Grubska-Suchanek, Roman Nowicki 